\title{
Training Faculty To Use Technology In The Classroom
}

Robert C. Zelin II, (E-mail: Robert.zelin@mnsu.edu), Minnesota State University, Mankato Jane E. Baird, (E-mail: jane.baird@mnsu.edu), Minnesota State University, Mankato

\begin{abstract}
Universities across the globe have in recent years been presented with unparalleled opportunities associated with advances in technology, but these opportunities are paired with numerous challenges. One such challenge is to ensure that faculty and staff are adequately trained in the new technologies. This paper describes the efforts of one College of Business in the Midwestern United States to prepare its faculty to operate in a technologically advanced environment in which both faculty and students use laptop computers in the classroom. This paper details the process the College went through to design and implement the training program and discusses the challenges and accomplishments of the program.
\end{abstract}

\section{INTRODUCTION}

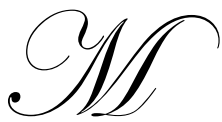

anaging change in any organization can be quite difficult, and higher education is no exception. Keeping pace with technology can be virtually impossible for faculty members with demanding teaching, research, and service schedules and limited university funding. This paper reports on the experience of one College of Business in preparing its faculty to teach in a technologically advanced environment. Because faculty readiness was perceived as a key component of success for the college's technology initiative, a faculty committee was charged with the responsibility of designing a training program. Design difficulties included limited financial resources, disparate faculty technological skills, lack of conformity of current faculty equipment and software, scheduling issues, and discipline-specific training needs.

\section{THE TECHNOLOGY INITIATIVE AT ONE UNIVERSITY}

The faculty members in the College of Business at a medium-sized state university in the Midwest voted to create a technologically-advanced environment for their students. The College at that time had only one dedicated computer classroom, and all of the University's computer facilities were stretched beyond their limits. Additionally, the University had no funds available for improving the situation. It became clear that this technology initiative would require innovative solutions to expanding the technological resources available for the College's faculty and students. The choice was made to raise private funds for classroom renovation, technology support, and network equipment, while requiring students to lease laptop computers. It was hoped that the use of computers by faculty members and students in the classroom would create an exciting active learning environment and that the laptops would allow for flexible use by students and faculty outside of the classroom.

The College of Business faculty decided that a pilot program with voluntary classes would commence during the Fall 2000 semester and that all sophomore level classes would be using the technology one year later. Under the pilot program, eight courses with seven different professors would be offered in the fall semester, and eight courses with six professors would be offered in the spring semester. The next step was to develop a training program to ready the College's faculty members for their new responsibilities. 


\section{WHY DEVELOP A FACULTY TRAINING PROGRAM?}

In order for a university to produce graduates who are highly skilled in the use of technology, the faculty teaching those students must be proficient enough in the use of the technology to incorporate it into the curriculum. Cummings and Buzzard (2002) found that employers prefer hiring students with superior technological skills. Hiring employees with the proper skills can often reduce the employers' cost of expensive technology classes. Cummings concluded that faculty training in the technology area is necessary and should be based on small groups involved in practical hands-on training on an ongoing basis.

In recent years, many institutions from primary schools through universities have attempted to incorporate more technology into the curriculum. A common stumbling block seems to be that many teachers and faculty are not prepared or confident enough in the use of technology to incorporate it into the courses they teach (Ali, 2003; Ashenfelter, 1997; Benson, 1997; Coley et al., 1997; Ellington, 1999, Fayter, 1998; Marx, 2005; Rups, 1999; Stevens and Lonberger, 1998; Thompson, Schmidt, \& Hadjiyianni, 1995; Thurlow, 1999; Topp, Mortenson, \& Grandgenett, 1995; Wetzel, 1993). Therefore, institutions have sought to develop technology training programs for their faculties. In a study that utilized faculty interviews in order to determine perceptions of technology and the adoption of technology in the classroom, Ali (2003) stated that "results suggested that many faculty members lack the motivation, opportunity or training to use technology and, most importantly, that the focus must shift from providing technology first to training faculty members first if they are to successfully use technology.”

\section{DEVELOPMENT OF A FACULTY TRAINING CURRICULUM}

In order to prepare the faculty for the transition, a training committee was formed one year before the start of the pilot program. The mission of the committee was to develop a training program that would enable the faculty to make a smooth transition into a computer intensive classroom environment. The committee had seven members representing all major departments within the College of Business.

The faculty training program followed a course of action similar to the Technology Learning Cycle (TLC). The model is based on the premise that instructors who use technology as a teaching tool are individuals who are constantly attempting to learn and effectively incorporate new technologies into an educational setting (Technology Learning Cycle, 2007). The TLC has five phases: awareness; exploration and filtration; learning; personal and professional application; and sharing and reflection. In the awareness phase, learners discover new technologies from a variety of sources, such as educational publications, educational conferences, the Internet and the general media. In the second phase, exploration and filtration, learners choose a technological innovation from their awareness list developed in the first phase. In the learning phase, learners are instructed how to use the selected technological innovation and are made aware of its pedagogical applications. During the personal and professional application phase, the learner incorporates the technological innovation into her or his course curriculum. In the last phase, sharing and reflection, the learner shares her or his experience with the technological innovation with others and reflects on the impact of the innovation (Technology Learning Cycle, 2007).

Prior to the initial meeting of the training committee, the chairperson of the committee compiled a notebook with information that would aid the committee members in designing the technology-related curriculum for the faculty. The notebook was divided into various sections. The first section contained an explanation of the Technology Initiative, the equipment that would be available, and the options under consideration for classroom design. A list of possible uses of technology in the classroom, which had previously been developed by the entire College faculty, was also included. Another section provided information about what other universities were doing with their notebook computer initiatives. This section included articles and information found on the Internet with regard to each of the universities. Other sections included information on upcoming conferences, potential speakers, self-study courses offered by Microsoft, and multimedia support available from textbook publishers. The final section contained information about various online classroom management products such as BlackBoard and WebCT. This notebook was developed to facilitate the "awareness" phase of the TLC. 
After reviewing the material, the committee began to brainstorm about faculty needs and training sessions that might be useful for faculty members. A long list was prepared. This was essentially the beginning of the "exploration and filtration" stage of the TLC. At the second meeting, the Committee members attempted to design a training taxonomy based on anticipated faculty needs. The main categories constructed were: how to use the laptop computer and the newly designed classrooms, how to use the various components of Microsoft Office software, how to incorporate what other technologically-advanced universities are doing, how to use online classroom management products and how to use multimedia products. This taxonomy and the development of specific courses were designed in consideration of several issues:

- $\quad$ Those faculty members participating in the pilot program must be adequately trained by the next fall, while the other faculty members had from one to three years to prepare, depending on the courses they taught. Therefore, an intense training schedule needed to be implemented for the pilot program faculty while also addressing the long-range needs of the other faculty members.

- $\quad$ The faculty possessed a wide range of skill and knowledge levels in regard to technology uses and the resources available. Several faculty members were migrating over from an Apple environment and several faculty members were a generation or two behind in software applications. Therefore, very rudimentary training was necessary for some faculty, while other faculty were ready for more advanced courses.

- $\quad$ The college offers courses in several business related disciplines, so the issue arose as to whether general technology training was adequate, or whether discipline specific training would also be necessary.

- $\quad$ Training sessions would need to be offered at times when most faculty members would be able to attend. Training could be offered during regular school days throughout the year, or in concentrated "training camps” during school breaks. However, no funds were available for compensating faculty for training during non-class days.

- $\quad$ The most desirable location for training sessions had to be determined.

- $\quad$ The matter of who would teach the training courses had to be decided. Options included College faculty, faculty from other universities, technology-support staff at the University, or representatives from the online classroom product companies.

- $\quad$ The training would need to incorporate how the technology would be utilized to aid instruction. Ranker and Clay (2002) found that professors were not interested in learning "latest" technology if it did not help them in the classroom.

- $\quad$ Faculty members have limited time and time spent on incorporating new technologies into the classroom is often not rewarded in the tenure and promotion process (Marx, 2005). Marx aided in the development of a faculty training program in technology at a branch of San Diego State University. He concluded that in order for a program to be successful, it should have the following components: small workshops on technologyrelated topics of interest to faculty members, individual tutoring/assistance, faculty member incentives to participate in workshops and an expanding information systems infrastructure.

- $\quad$ At the time the technology initiative was developed, it was strictly focused on use of technology in the classroom, with no need for development of totally online courses. Therefore, training for distance learning applications was not a priority (for information on training for online instruction, see Hoffman and Ritchie (1998), MacFarland (1998), Martin (1997), McKinzie and McCallie (1999), SchWeber et al. (1998), and Thoms (1997)).

A schedule for the period December to April was constructed, taking into account the above factors. The committee decided that it would be too difficult to motivate the faculty to attend training on non-duty days without providing them with additional compensation. It was also decided that shorter sessions spread throughout the year would allow the faculty members to practice the techniques they learned from each session before moving ahead to the next training. Twelve sessions were offered with four of the sessions being repeats of previous sessions. These sessions were repeated to allow for scheduling conflicts and to allow the more novice technology users to repeat sessions if they desired. The sessions were offered during final examination week of that same semester, two days prior to the start of the following semester, and throughout the semester on Friday afternoons from 2 p.m. to 4 p.m.. The Friday afternoon session time was selected because it was the only time slot during the week in which no classes were offered. 
The committee determined that a variety of training courses needed to be offered to address the wide range of information needs and skill levels of the faculty. The training, or "learning" phase of the TLC, would begin with the basics and then branch out into specific applications. The curriculum included sessions addressing the care and use of the laptop computer, how laptops were used in the classroom at two other universities, the primary uses of Microsoft Excel, PowerPoint and FrontPage and how online classroom management systems could be used in the classroom. Individual help sessions with technology support staff would be offered for faculty volunteering for the pilot program, as needed. Discipline-specific training, if desired, would be left to the individual departments to design.

The committee decided that the best location for training would be in the notebook computer classrooms, so that faculty would become familiar with those rooms. However, while those rooms were being remodeled, training would be held in the College's computer classroom. In order to minimize costs and faculty member time commitment for the college, the committee decided to utilize the technology support staff on campus as much as possible to teach the training, as well as other no-cost training providers such as the textbook publishing companies and on-line classroom product providers. Each of the training sessions offered is described in the following sections.

\section{TRAINING SESSIONS OFFERED PRIOR TO PILOT PROGRAM (IN CHRONOLOGICAL ORDER)}

\section{Orientation -Notebook Use And Maintenance}

The purpose of this two hour session was to distribute the notebook computers and to familiarize faculty members with the features of the IBM notebook computer and the features of the Windows operating system. All faculty members had been using desktop computers. The majority of the computers were IBM compatible, but approximately 12.5 percent were produced by Apple Computers. In addition, many of the PC users had been using the Windows 3.1 operating system and thus had to move forward two generations. The session was designed to move slowly so that all faculty members, regardless of their technology background, could absorb the material being presented. The course was conducted by individuals from the Computing Services department within the university. The orientation session was mandatory for all faculty members. Faculty members missing the session were not given their notebook computers until they watched a two hour video of the orientation session.

\section{IBM/Concordia College Laptop Project Presentation}

At this two-hour training session, representatives from IBM informed the faculty about various IBM ThinkPad programs at other universities. The representatives talked about how the technology was being used in the classroom. During the second half of the training session, the Director of the Notebook Computer Project at Concordia College in St. Paul, Minnesota, told the assembly how the notebook computers were being used at his college. The purpose of this training session was to provide faculty members with information from other universities and to aid them in the development of a vision as to how they might use the technology in the classroom.

\section{Introduction To Microsoft Office Software}

\section{- $\quad$ PowerPoint (Two sessions offered) \\ - $\quad$ FrontPage (Two sessions offered) \\ - $\quad$ Excel (Two sessions offered)}

The training committee felt that the above three software products would be heavily used in a technologically advanced environment. Introductory sessions were necessary because of the faculty members who were migrating from the Apple environment and the faculty members who were leaping forward two generations with the Microsoft Office software. The PowerPoint course covered the basics of putting together a presentation, and was taught by a computer services staff member on campus. The FrontPage course was taught by a College of Business professor. The Excel course was taught by a campus computer services staff member. 


\title{
Online Classroom Products
}

\author{
- $\quad$ Irwin/McGraw-Hill Seminar \\ - $\quad$ ITP/Southwest Publishing Seminar
}

The purpose of the two seminars was to familiarize faculty members with two online classroom products, specifically WebCT and BlackBoard, and to acquaint faculty members with the related online classroom products that the publishers had to offer. Faculty members viewed online classroom components such as syllabus posting, class notes posting, discussion groups, online testing, and grade posting. These classes were taught by representatives from the publishing companies at no charge to the College.

\section{Winona State University Laptop Project Presentation}

Two professors from the Marketing Department at Winona State University (Minnesota) conducted this twohour seminar. Winona State had begun using laptops in their courses, on a phase-in basis, the previous year. Each professor talked about how he used technology in the classroom. This seminar allowed faculty members to learn about the use of laptop computer technology at another University similar to their own.

\section{TRAINING OFFERED DURING PILOT PROGRAM}

It was decided that eight training sessions would be offered during the first semester of the pilot program. The sessions broached the topics of how to use the newly constructed multimedia classrooms, how to use electronic communication tools such as Outlook, NetMeeting and FrontPage, how to digitize material and produce videos and how to produce effective Web pages. All of the sessions were taught by individuals from the Department of Instructional Technology at the university. The sessions were offered at no cost to the college. At this point in the training program, the program itself moved into the "personal and professional applications" phase in that some faculty were beginning to teach in the pilot program and apply what they were learning about the technology to their teaching. However, those faculty who were not teaching in the pilot program were still in the "awareness", "exploration and filtration" or "learning" phases, depending on how involved they had been in the early training sessions. Therefore, as the program progressed, the committee had to approach the TLC through somewhat of a reiterative process in order to meet the needs of those faculty who had moved into the application phase while bringing along those faculty who were just starting to get involved in the training.

\section{How To Use Wireless Cards And The Multimedia Classrooms}

During this seminar, faculty members were trained in the use of the wireless network and the other equipment in the classroom. Both classrooms were outfitted with projection devises, a station for the professor that included a laptop docking station, video equipment, an amplifier with speakers, and a document camera. Each room also contained a high-speed printer that could be accessed by faculty and students through the wireless network. Additionally, a SmartBoard could be found in each room. The SmartBoard has the appearance of a white board and serves as the projection screen. When engaged the SmartBoard is touch sensitive which allows a finger to be used instead of a mouse. Additionally, information written on the SmartBoard can be saved as a file and distributed to class members. Faculty members were first shown how to use the equipment and then were given an opportunity to practice on the equipment themselves.

\section{Electronic Communication}

- $\quad$ Introduction to NetMeeting and Outlook Express

- $\quad$ NetMeeting and Using FrontPage to Create A Discussion Group

- $\quad$ Managing and Implementing Computer Conferencing 
The purpose of the above sessions was to expose faculty members to electronic means of communicating with each other and with students. The training committee and the architects of the technology initiative envisioned that the notebook computers would be used outside the classroom more than inside the classroom and that the notebook computers would foster a sense of greater access to a faculty member. These seminars provided faculty members with three different methods of communication with students.

\section{Digitizing Media}

- $\quad$ Effective Use of a Digital Camera and Scanner

- $\quad$ Digitizing Video

These two sessions aided faculty members in the introduction of pictures, documents and videos into the classroom/curriculum via electronic means. Seminar participants were shown how to capture, scan, digitize and edit material; upload images from a digital camera; and capture, digitize and edit video clips.

\section{Front Page}

- $\quad$ Skills workshop Level I

- $\quad$ Skills workshop Level II

For faculty members who wanted more of a presence on the Internet, these seminars aided them in the basic principles of Web page planning and construction. Participants learned how to create multiple pages, create links to other pages or sites and introduce graphics and images into a Web page.

\section{Panel Discussion By Professors In The Pilot Project}

Seven Professors participated in the pilot program representing the areas of accounting, marketing and management information systems. The professors shared how they used technology in the classroom. Products/Methods mentioned included online classroom systems (syllabus, class notes and assignment posting; discussion groups; and grade posting), Internet course pages, PowerPoint usage (by professor and students), Excel Usage, and SPSS usage. The professors all stated that they enjoyed the new classroom environment and found the students to be excited and motivated. However, the professors also highlighted some of the classroom problems, such as not knowing whether the student was taking notes or simply playing a game or sending an electronic mail message; technology breakdowns in the classroom (i.e. printer problems, sound system problems, faculty member's or student's computer hardware or software problems); and online classroom system problems. The professors also talked about the significant increase in their preparation time for class.

\section{POST-PILOT PROGRAM TRAINING}

After the initial pilot year intensive training program, the focus and intensity of training changed immensely. The faculty members were, for the most part, teaching laptop courses and were familiar with the equipment and the software to be used in their courses. The focus of training efforts then shifted to discussion-based forums of how to effectively use the technology to improve learning in the classroom. Faculty continued to share ideas in these discussion forums for innovative pedagogy utilizing the laptops. Faculty roundtable sessions were conducted in which professors shared their successful strategies and concerns that had arisen after experience teaching with the laptops. Topics of these discussions included successful ways of incorporating active learning using the laptops; specific course activities used in the classroom such as online surveys, incorporating and researching current news items and company information, hands-on use of applications, and use of simulations in class; how to keep students on task with all the distractions possible through wireless Internet access; and how to prevent cheating in a laptop environment. This phase of the training program corresponds to the "sharing and reflection" phase of the TLC. Faculty still had an opportunity for basic software training at the University level, but this training was no longer deemed necessary at the College level. Training on the use of classroom equipment for new faculty or faculty coming 
into the laptop program in the latest phase was conducted on an individual, as-needed basis only. In addition, publishers were brought in periodically to demonstrate the newest available technological products.

\section{Challenges And Successes}

This training program both achieved successes and experienced challenges. The College was able to successfully prepare its pilot program faculty to deliver the first courses in the laptop environment and then bring the entire program to fruition within two years. Faculty began a dialogue of ways to incorporate the technology into the curriculum to improve student learning, which was the ultimate goal of the initiative.

Faculty attendance at the training sessions was a challenge. Throughout the training program, the courses were typically attended by the same group of individuals who were excited about adopting the new technology. On average, approximately 30 percent of the faculty attended each session. A few professors did not attend any of the training sessions. Since all faculty members teach in the laptop environment, this is a significant concern. Another shortcoming of the training was a failure to reach adjunct instructors who are not regularly on campus. One possible solution is to videotape the training sessions for the adjunct instructors, but this does not totally replicate the hands-on experience of the training sessions. Additionally, the adjunct instructors typically teach just one class each per semester and receive very moderate compensation, so there is little incentive to offer them to spend the additional time needed to prepare to teach in the laptop environment.

Another challenge encountered was with faculty not having enough spare time after each training session to practice what they had learned (a similar problem was noted in Formosa (1998)). This is especially a problem for the faculty members who were not part of the pilot program and did not teach laptop courses for another year. These professors needed refresher courses as they finally got to the stage when they were developing their laptop courses.

Yet another challenge was in the delivery of the training sessions. Because the faculty members were coming into the sessions with a wide disparity in technology skills, the first sessions were intentionally designed to be basic foundations or introductions. Still, some faculty encountered problems and needed special assistance from the instructors, causing the entire class to get behind schedule. At other times, a professor would ask a more advanced question and get the instructor off the schedule while also confusing the more novice users in the room. Sessions seemed to go more smoothly when the instructor also had technical assistants in the room to help individual faculty. Formosa (1998) encountered similar difficulties and concluded that individual training sessions must be made available for some faculty.

The focus of these first training sessions was to provide faculty with a basic set of skills in using the new technology and to present various ideas as to the types of activities that could be included in the classroom and the resources available. However, some faculty expressed the need for more tailored sessions describing in more detail activities they could use in their specific courses. An example would be a course specifically dealing with technology uses in financial accounting courses. While the basic training was a necessary first step to bring the faculty up to an acceptable level of competence and confidence with the technology (Stevens and Lonberger, 1998), future training in the specific disciplines will likely be helpful in assisting faculty vision of how to improve learning in their courses through the use of technology (see Littlejohn and Sclater, 1998 and Formosa, 1998).

The training program curriculum evolved as more professors began teaching the laptop courses and more feedback was received from faculty and students. The College continues to sponsor sharing mechanisms such as panel discussions to generate ideas for improving learning through the technology, discipline-specific sessions, and ongoing technical training as needed. While the challenges of embarking on this type of adventure are many, the rewards can be tremendous as well. 


\section{REFERENCES}

1. Ali, A. (2003). Faculty Adoption of Technology: Training Comes First, Educational Technology, 43 (2), $51-53$.

2. $\quad$ Ashenfelter, J.P. (1997). Strategies for Introducing Faculty with Limited Computer Skills to Web-Based Instructional Projects: Case Studies in Drama and the Classics, Journal of Instruction Delivery Systems v11 n4, p. 14-18.

3. $\quad$ Benson, D. (1997). Technology Training: Meeting Teachers' Changing Needs. Principal. 76(3), p. 17-19.

4. Coley, R.J., Cradler, J., and Engel, P. (1997). Computers and Classrooms: The Status of Technology in U.S. Schools. ETS Policy Information Center, Princeton, N.J.

5. Cummings, D. and Buzzard, C. (2002). Technology, Students and Faculty...How to Make it Happen!, Techniques, 77(8), p. 30-33.

6. Ellington, H. (1999). Reconciling Conflicting Demands in the Training of HE Teachers-The Experience at the Robert Gordon University, Education + Training v41 n1, p. 27-32.

7. Fayter, D. (1998). Issues in Training Lecturers to Exploit the Internet as a Teaching Resource, Education + Training v40 n8, p. 334-339.

8. Formosa, Jim. (1998). Are You Sure You Want To Train Faculty To Develop Web-Based Instruction?, Proceedings of the 1998 Mid-South Instructional Technology Conference, Murfreesboro, Tennessee. ERIC Microfiche ED431387.

9. Hoffman, Bob and Donn Ritchie. (1998). Teaching and Learning Online: Tools, Templates, and Training Proceedings of SITE 98: Society for Information Technology and Teacher Education International Conference, Washington, DC, ERIC Microfiche ED421092.

10. Littlejohn, Allison and Niall Sclater. (1998) Overcoming Conceptual Barriers to the Use of Internet Technology in University Education, Proceedings of the WebNet 98 World Conference of the WWW, Internet and Intranet, Orlando, Florida. ERIC Microfiche ED427717.

11. MacFarland, Thomas W. (1998). Assessment of an Internet Training Program for Distance Education Adjunct Faculty, presented at the Annual Conference of the National Adjunct Faculty Guild, Chicago, IL., ERIC Microfiche ED418698.

12. Martin, Merle. 1997. The Virtual Classroom: The Next Steps. Educational Technology, v37 n5, p. 51-55.

13. Marx, S. (2005). Improving faculty Use of Technology in a Small Campus Community, T.H.E. Journal, (January), p. 21-23.

14. McKinzie, LeAnn and Trey McCallie. (1999). Teaching Online: A Professional Development Model, ERIC Microfiche ED432247.

15. Ranker, R.A. and Clay, M.B. (2002). A Department-Focused Plan for Faculty Technology Professional Development, Educause Quarterly, (4), p. 52-55.

16. Rups, Pamela. (1999). Training Instructors in New Technologies, T.H.E. Journal v26 n8, p. 66-69.

17. SchWeber, Claudine, Kimberly Kelley, and Gloria Orr. (1998). Training, and Retaining, Faculty for Online Courses: Challenges and Strategies, Distance Learning '98: Proceedings of the Annual Conference on Distance Teaching and Learning, Madison, WI. ERIC Microfiche ED422874.

18. Stevens, Carol and Rosemary Lonberger. (1998). Using Technology in Instruction: Supporting Teacher Education Faculty Development. Proceedings of SITE 98: Society for Information Technology and Teach Education International Conference, Washington, DC., ERIC Microfiche ED421131.

19. Technology Learning Cycle, Retrieved March 1, 2007 from http://www.coe.missouri.edu/ tlc/.

20. Thompson, A., Schmidt, D., \& Hadjiyianni, I., (1995). A three year plan to infuse technology throughout a teacher education program. Journal of Technology \& Teacher Education, 3(1), p. 13-24.

21. Thoms, Karen Jarrett. (1997). A Systematic Approach to Training Faculty to Teach via a Two-Way Interactive Television System, Proceedings of the Mid-South Instructional Technology Conference, Murfreesboro, Tennessee. ERIC Microfiche ED430517.

22. Thurlow, John P. (1999). Teachers as Technologists: Professional Development for Technology Integration, ERIC Microfiche ED429581.

23. Topp, N. W., Mortenson, R., \& Grandgenett, N. (1995). Building a technology-using faculty to facilitate technology-using teachers. Journal of Computing in Teacher Education, 11(3), p. 11-14.

24. Wetzel, K. (1993). Teacher educators' uses of computers in teaching. Journal of Technology \& Teacher Education, 1, p. 335-352. 